\title{
Pengaruh Perlakuan Panas Terhadap Sifat Mekanis dan Struktur Mikro Paduan Alumunium Silikon
}

\author{
Ahmad Zubair Sultan ${ }^{*}$, Abram Tangkemanda², Irsyad Amru Djafar ${ }^{3}$, Rio Triwanto \\ Rantepadang ${ }^{4}$ \\ 1,2,3,4 Jurusan Teknik Mesin, Politeknik Negeri Ujung Pandang, Makassar 90245, Indonesia \\ *ahmadzubairsultan@poliupg.ac.id
}

\begin{abstract}
The use of aluminum silicon alloys as automotive components is growing along with the growing desire to reduce the weight of the components used. However, aluminum alloys still have low mechanical properties, so other processes are needed to increase their hardness, one of them by heat treatment process. This alloy material is commonly used for motorcycle piston. This study aims to determine the effect of heat treatment on mechanical properties and microstructure of Aluminum Silicon A383 using the age hardening method with variations in aging temperature and different holding times. The testing of mechanical properties is done by testing the hardness and thermal conductivity. From the testing results, composition of aluminum alloy A383 composed of $73.30 \%$ aluminum, 22.08\% silicon and highest hardness $105.9 \mathrm{HB}$ at an aging temperature $200^{\circ} \mathrm{C}$ within 30 minutes and the optimal value of the hardness and thermal conductivity of the aging variations performed are at temperature $200^{\circ} \mathrm{C}$ at holding time 88 minute. As the aging temperature increases, the hardness of aluminum increases and amount of silicon also increase.
\end{abstract}

Keywords : aluminium silicon alloy a383, age hardening, hardness, microstructure, optimation

\begin{abstract}
Abstrak: Penggunaan paduan aluminium silikon sebagai komponen otomotif semakin berkembang bersamaan dengan semakin berkembangnya keinginan untuk mengurangi berat dari komponen yang digunakan. Namun paduan aluminium silikon masih memiliki sifat mekanis yang rendah sehingga diperlukan proses lain untuk meningkatkan kekerasannya, salah satunya melalui proses perlakuan panas. Bahan paduan ini biasa dipakai untuk torak motor. Penelitian ini bertujuan untuk mengetahui pengaruh dari peralakuan panas terhadap sifat mekanis dan struktur mikro pada Aluminium Silikon A383 menggunakan metode age hardening dengan variasi temperatur aging dan waktu penahanan yang berbeda. Dari hasil pengujian, komposisi paduan aluminium A383 tersusun dari aluminium $73,30 \%$, silikon $22,08 \%$, kekerasan tertinggi $105,9 \mathrm{HB}$ pada temperature aging $200^{\circ} \mathrm{C}$ dalam 30 menit dan nilai optimal kekerasan dan konduktivitas termal dari variasi aging yang dilakukan adalah pada suhu $200^{\circ} \mathrm{C}$ dan waktu penahanan 88 menit. Seiring penambahan suhu aging, kekerasan aluminiumpun turut bertambah, dibarengi dengan penambahn jumlah unsur silicon
\end{abstract}

Kata kunci : aluminium silikon A383, age hardening, kekerasan, struktur mikro, optimasi.

\section{PENDAHULUAN}

Aluminium memiliki banyak kelebihan, salah satunya yaitu paduan aluminium silikon yang biasanya digunakan untuk komponen-komponen otomotif seperti piston pada berbagai kendaran bermotor[1]. Piston mengalami beban yang besar selama mesin hidup, yaitu mendapat tekanan tinggi saat melakukan langkah kompresi dan mendapat pemanasan tinggi dan tekanan tinggi saat pembakaran dan saat langkah kerja. Oleh karena itu, material yang dibutuhkan piston merupakan material dengan spesifikasi khusus, yaitu paduan Aluminium Silikon(Al-Si) [1,2]. material ini dipilih karena memiliki kekuatan tinggi, koefisien muai rendah, dan juga memiliki daya tahan terhadap abrasidan korosi, salah satu metode untuk meningkatkan kekekerasan suatu logam yaitu heat treatment, dengan proses heat treatment ini diharapkan dapat menghasilkan aluminium silicon dengan tingkat kekerasan dan daya hantar panas yang lebih baik dari sebelumnya. Berdasarkan uraian teori diatas maka Proses heat treatment telah biasa dilakukan pada paduan aluminium untuk meningkatkan kekuatan dan konduktivitasnya. Pada penelitian ini akan dilakukan dengan menggunakan aluminium silikon A383. 


\section{METODE PENELITIAN}

\section{Persiapan Bahan dan Alat}

Bahan yang digunakan pada penelitian ini berupa benda uji aluminium silicon A383 sebanyak 12 batang yang berbentuk balok dengan dimensi (20x10x10) $\mathrm{mm}$. Peralatan yang digunakan diantaranya : Chamber furnace N 41/H, Hardness Tester (Affri Universal Hardness Tester),Mesin polishing/grinding, alat uji konduktivitas, mikroskop elektronik (Meiji Techno)

\section{A. Prosedur Penilitian}

Pembuatan spesimen uji berupa Aluminium Silikon A383. Spesimen dipotong menjadi 12 Sampel Dengan ukuran 10x10x20mm. Untuk memastikan komposisi spesimen dilakukan uji komposisi kimia dengan menggunakan metode XRF. Setelah itu, spesimen uji sebanyak 11 sampel dimasukkan kedalam furnace dengan temperature $550^{\circ} \mathrm{C}$ selama $2 \mathrm{jam}$, lalu spesimen dikeluarkan dari furnace dan didinginkan secara cepat (quenching) dengan menggunakan media air, lalu dilakukan proses age hardening dengan variasi temperature dan waktu penahanan

Pengujian berikutnya yaitu uji kekerasan. Uji kekerasan ini dilakukan dengan metode Brinnel (HB10) dengan penetrartor bola berdiameter $2,5 \mathrm{~mm}$, dan pembebanan $613 \mathrm{~N}$, sebelum dilakukan pengujian kekerasan permukaan, specimen diratakan dan dihaluskan terlebih dahulu menggunakan amplas Selanjutnya adalah pengujian struktur mikro, specimen terlebih dahulu dihaluskan permukaannya hingga rata dan mengkilap dengan menggunakan mesin grinding dan dipolish menggunakan kain beludru dan pasta. Setelah didapatkan permukaan specimen yang halus dan mengkilap selanjutnya, permukaan specimen dicelupkan pada cairan etsa HF $0,5 \%$ agar struktur mikro dapat telihat dengan jelas Pengamatan Struktur Mikro ini dilakuan dengan pembesaran lensa 20X. Pengujian yang terakhir adalah melakukan uji konduktivitas.

\section{B. Analisis Data}

Data hasil pengujian kekerasan, struktur mikro, konduktivitas termal, selanjutnya diolah menggunakan software design expert untuk mengetahui keterkaitan antara temperature dan waktu penahanan (holding time)

\section{HASIL DAN PEMBAHASAN}

A. Hasil

Komposisi Kimia hasil pengujian terhadap Aluminium Silikon A383 dapat dilihat pada Tabel 1. Tabel 1. Komposisi Kimia Aluminium A383

\begin{tabular}{|c|c|c|c|c|c|}
\hline Elemen & $\mathbf{A l}$ & $\mathbf{S i}$ & $\mathbf{C u}$ & $\mathbf{F e}$ & $\mathbf{M n}$ \\
\hline$\%$ & 84.54 & 10.54 & 2.2 & 1.15 & 0.497 \\
\hline
\end{tabular}

Data Nilai Kekerasan Aluminium A383 pada Tabel 2. adalah hasil percobaan dengan variasi temperature dan waktu aging

Tabel 2: Hasil Percobaan Kekerasan dengan variasi temperature dan waktu aging

\begin{tabular}{|c|c|c|c|c|c|c|c|c|}
\hline \multirow{2}{*}{ NO } & \multirow{2}{*}{ Suhu } & \multirow{2}{*}{$\begin{array}{c}\text { Holding } \\
\text { Time }\end{array}$} & \multicolumn{5}{|c|}{ Kekerasan (HB10) } & \multirow{2}{*}{$\begin{array}{c}\text { rata- } \\
\text { rata }\end{array}$} \\
\hline & & & 1 & 2 & 3 & 4 & 5 & \\
\hline 1 & $100^{\circ} \mathrm{C}$ & $0.5 \mathrm{jam}$ & 93.9 & 90.2 & 96.6 & 93.2 & 95.2 & 93,82 \\
\hline 2 & $100^{\circ} \mathrm{C}$ & 1,5 jam & 88 & 85 & 93.5 & 97.2 & 95.2 & 91.78 \\
\hline 3 & $100^{\circ} \mathrm{C}$ & 2,5 jam & 70.4 & 73 & 77.6 & 83.3 & 75.1 & 75.88 \\
\hline 4 & $150^{\circ} \mathrm{C}$ & 0,5 jam & 97.3 & 91.1 & 97.8 & 100.8 & 99.6 & 97.32 \\
\hline 5 & $150^{\circ} \mathrm{C}$ & 1,5 jam $(\mathrm{A})$ & 84.3 & 87.4 & 81.6 & 80.9 & 82.6 & 83.36 \\
\hline 6 & $150^{\circ} \mathrm{C}$ & 1,5 jam (B) & 86.7 & 90.2 & 95 & 99.3 & 91.7 & 92.58 \\
\hline 7 & $150^{\circ} \mathrm{C}$ & 1,5 jam $(\mathrm{C})$ & 81.3 & 80.5 & 79.7 & 86.7 & 81.4 & 81.92 \\
\hline
\end{tabular}


205 Ahmad zubair Sultan, abram tangkemanda, Irsyad Amru Djafar, Rio Triwanto Rantepadang. Pengaruh Perlakuan Panas Terhadap Sifat Mekanis dan Struktur Mikro Paduan Alumunium Silikon

\begin{tabular}{|c|c|c|c|c|c|c|c|c|}
\hline 8 & $150^{\circ} \mathrm{C}$ & $2,5 \mathrm{jam}$ & 85.5 & 99 & 95.2 & 98.7 & 99.6 & 95.6 \\
\hline 9 & $200^{\circ} \mathrm{C}$ & $0,5 \mathrm{jam}$ & 114 & 111.6 & 105.9 & 112.4 & 109.2 & 110.62 \\
\hline 10 & $200^{\circ} \mathrm{C}$ & $1,5 \mathrm{jam}$ & 83.5 & 81.5 & 86.7 & 79.3 & 85.7 & 83,3 \\
\hline 11 & $200^{\circ} \mathrm{C}$ & 2,5 jam & 75.60 & 74.30 & 78.70 & 82.10 & 69.70 & 76.08 \\
\hline 12 & \multicolumn{2}{|c|}{ Tanpa Heat Treatment } & 60.9 & 76.8 & 83.7 & 85 & 85.2 & 78.32 \\
\hline
\end{tabular}

Data konduktivitas thermal Aluminium A383 dapat dilihat pada Tabel 3

Tabel 3: Hasil Konduktivitas thermal dengan variasi temperature dan waktu aging

\begin{tabular}{|c|c|c|c|}
\hline \multirow{2}{*}{ No } & Aging Temperature & Holding Time & Konduktivitas Thermal \\
\cline { 2 - 4 } & (C) & (minutes $)$ & $(\mathrm{W} / \mathrm{mK})$ \\
\hline 1 & 100 & 30 & 212 \\
\hline 2 & 100 & 90 & 206.9 \\
\hline 3 & 100 & 150 & 208.3 \\
\hline 4 & 150 & 30 & 205.5 \\
\hline 5 & 150 & 90 & 209.7 \\
\hline 6 & 150 & 90 & 209 \\
\hline 7 & 150 & 90 & 210 \\
\hline 8 & 150 & 150 & 215.3 \\
\hline 9 & 200 & 30 & 208.7 \\
\hline 10 & 200 & 90 & 241.8 \\
\hline 11 & 200 & 150 & 219.9 \\
\hline
\end{tabular}

Hasil Pengamatan Struktur Mikro dapat dilihat pada Tabel 4

Tabel 4: Struktur mikro terhadap suhu dan holding time

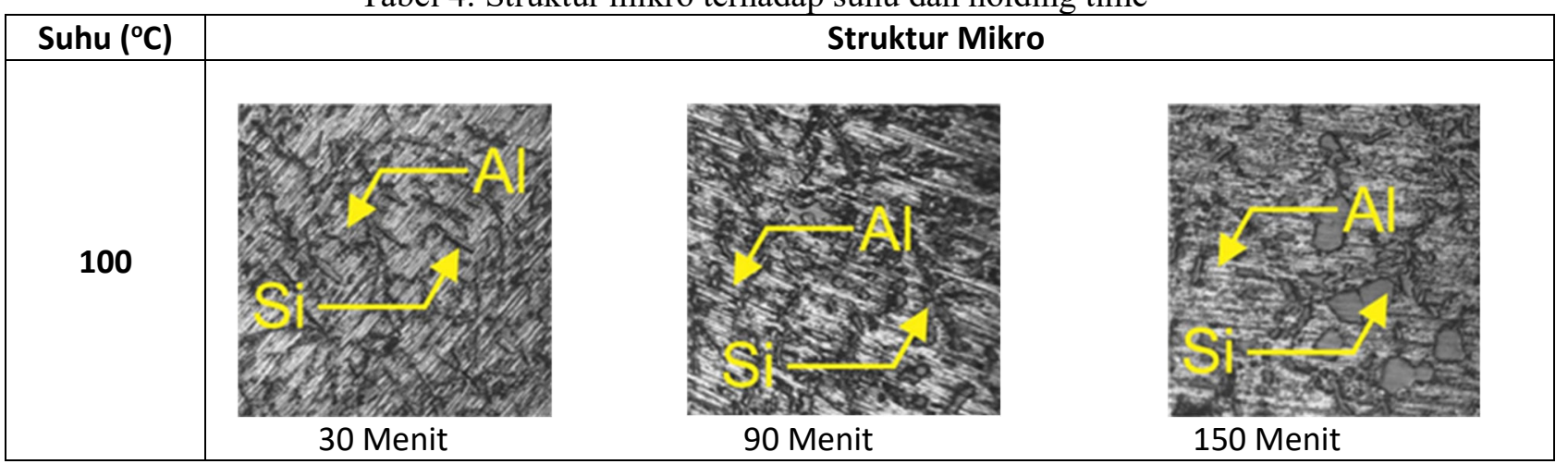




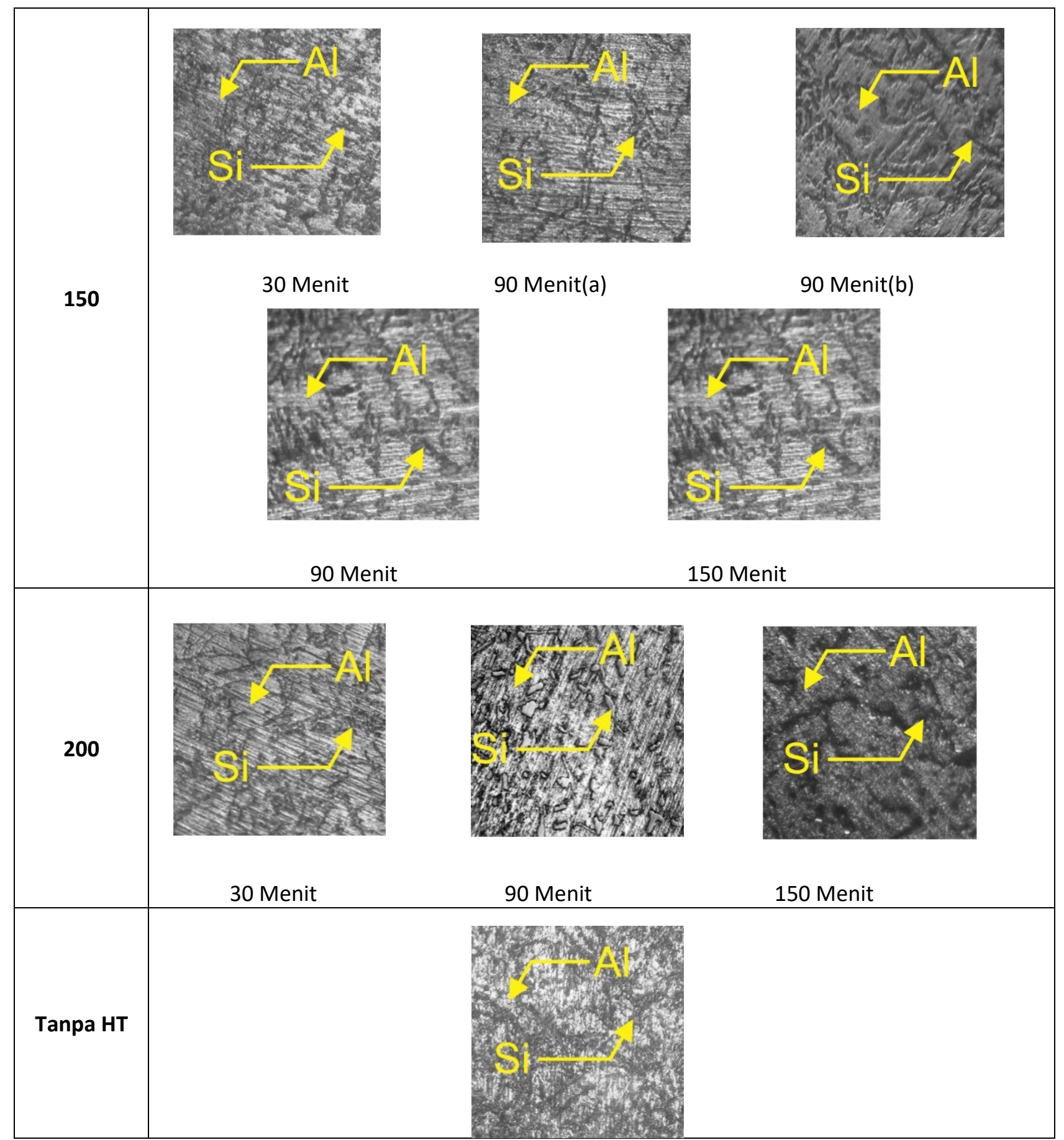

Dari gambar struktur mikro di atas, dapat dilihat bahwa raw material terdapat komposisi aluminium (Al) yang berwarna lebih cerah berada didasar permukaan dan silicon ( $\mathrm{Si}$ ) yang berwarna lebih gelap dengan guratan guratan. Berdasarkan pengamatan struktur mikro dapat dijelaskan sebagai berikut. Pada struktur mikro dengan temperatur aging $100{ }^{\circ} \mathrm{C}$, terlihat bahwa unsur silicon berbentuk serpihan kecil, tipis, dan pendek. Pada struktur mikro dengan temperatur aging $150{ }^{\circ} \mathrm{C}$, terlihat bahwa unsur silicon masi berbentuk serpihan kecil, agak tebal, dan pendek. Pada struktur mikro dengan temperatur aging $200{ }^{\circ} \mathrm{C}$, terlihat semakin jelas bahwa unsur Si berbentuk serpihan lebih besar, tebal, dan rapat. Perubahan temperature aging dari temperature rendah menuju temperature lebih tinggi 
207 Ahmad zubair Sultan, abram tangkemanda, Irsyad Amru Djafar, Rio Triwanto Rantepadang. Pengaruh Perlakuan Panas Terhadap Sifat Mekanis dan Struktur Mikro Paduan Alumunium Silikon

menyebabkan terjadinya perubahan struktur mikro, dimana struktur mikro tampak lebih besar dan tebal.

\section{B. Pembahasan}

Setelah memperoleh data nilai kekerasan dan kondutivitas, selanjutnya data akan diolah menggunakan software design expert, untuk mengetahui keterkaitan antara temperature dan waktu penahaan pada proses aging dengan nilai kekerasan dan konduktivitas thermal.

Tabel 5: Statistik kecocokan model untuk kekerasan [3,4]

\begin{tabular}{|c|c|c|c|c|c|c|}
\hline \multicolumn{7}{|c|}{ Response: Hardness } \\
\hline \multicolumn{7}{|c|}{ Sequential Model Sum of Squares } \\
\hline & Sum of & & Mean & $\mathbf{F}$ & & \\
\hline Source & Squares & DF & Square & Value & Prob $>F$ & \\
\hline Mean & 88794.26 & 1 & 88794.26 & & & \\
\hline Linear & 399.07 & $\underline{2}$ & 199.53 & $\underline{3.25}$ & $\underline{0.0927}$ & Suggested \\
\hline $2 \mathrm{FI}$ & 16.81 & 1 & 16.81 & 0.25 & 0.6337 & \\
\hline Quadratic & 64.14 & 2 & 32.07 & 0.39 & 0.6955 & \\
\hline Cubic & 188.08 & 2 & 94.04 & 1.27 & 0.3985 & Aliased \\
\hline Residual & 222.13 & 3 & 74.04 & & & \\
\hline Total & 89684.49 & 11 & 8153.14 & & & \\
\hline \multicolumn{7}{|c|}{ Lack of Fit Tests } \\
\hline & Sum of & & Mean & $F$ & & \\
\hline Source & Squares & DF & Square & Value & Prob $>F$ & \\
\hline Linear & 352.07 & $\underline{6}$ & 58.68 & $\underline{0.84}$ & $\underline{0.6317}$ & Suggested \\
\hline $2 \mathrm{FI}$ & 335.26 & 5 & 67.05 & 0.96 & 0.5800 & \\
\hline Quadratic & 271.13 & 3 & 90.38 & 1.30 & 0.4627 & \\
\hline Cubic & 83.04 & 1 & 83.04 & 1.19 & 0.3886 & Alased \\
\hline Pure Error & 139.09 & 2 & 69.54 & & & \\
\hline
\end{tabular}

Menurut hasil ANOVA pada Tabel 5, model adalah significant karena Prob $>$ F adalah kurang dari $\alpha(0.05)$ yang mengimplikasikan $95 \%$ derajat kepercayaan (confidence interval). Hasil juga menunjukkan bahwa temperatur aging (A) dan waktu tahan (B) adalah faktor signifikan yang mempengaruhi kekerasan[5,6]. Informasi lain bahwa tidak ada interaksi antara temperatur aging dan waktu tahan $(\mathrm{A} * \mathrm{~B})$. Berikutnya, ketidak cocokan model (lack of fit) adalah tidak signifikan karena nilai Prob $>$ F lebih besar dari $\alpha(0.05)$. 
Tabel 6: Statistik kecocokan model untuk konduktivitas termal[3,4]

\begin{tabular}{|c|c|c|c|c|c|c|}
\hline \multicolumn{7}{|c|}{ Sequential Model Sum of Squares } \\
\hline & Sum of & & Mean & $F$ & & \\
\hline Source & Squares & DF & Square & Value & Prob $>F$ & \\
\hline Mean & $4.894 E+005$ & 1 & $4.894 E+005$ & & & \\
\hline Linear & 93.62 & 2 & 46.81 & 4.37 & 0.0523 & \\
\hline$\underline{2 \mathrm{FI}}$ & $\underline{55.50}$ & 1 & $\underline{55.50}$ & $\underline{12.83}$ & $\underline{0.0089}$ & Suggested \\
\hline Quadratic & 12.67 & 2 & 6.34 & 1.80 & 0.2577 & \\
\hline Cubic & 16.89 & 2 & 8.44 & 35.58 & 0.0081 & Aliased \\
\hline Residual & 0.71 & 3 & 0.24 & & & \\
\hline Total & $4.895 E+005$ & 11 & 44502.79 & & & \\
\hline
\end{tabular}

\section{Lack of fit Tests}

$\begin{array}{rrrrrrr} & \text { Sum of } & & \text { Mean } & F & & \\ \text { Source } & \text { Squares } & \text { DF } & \text { Square } & \text { Value } & \text { Prob }>F & \\ \text { Linear } & 85.25 & 6 & 14.21 & 53.95 & 0.0183 & \\ \underline{2 F 1} & \underline{\underline{29.75}} & \underline{5} & \underline{5.95} & \underline{\underline{22.59}} & \underline{\underline{0.0429}} & \underline{\underline{\text { Sugoesited }}} \\ \text { Ouadratic } & 17.07 & 3 & 5.69 & 21.61 & 0.0445 & \\ \text { Cubic } & 0.19 & 1 & 0.19 & 0.70 & 0.4898 & \text { Alased } \\ \text { Pure Error } & 0.53 & 2 & 0.26 & & & \end{array}$

Model adalah significant menurut hasil ANOVA pada Tabel 6, karena Prob $>$ F adalah kurang dari $\alpha(0.05)$ yang mengimplikasikan $95 \%$ derajat kepercayaan (confidence interval). Hasil juga menunjukkan bahwa temperatur aging (A) dan waktu tahan (B) adalah faktor signifikan yang mempengaruhi konduktivitas termal. Informasi lain bahwa tidak ada interaksi antara temperatur aging dan waktu tahan $\left(\mathrm{A}^{*} \mathrm{~B}\right)$. Berikutnya, ketidak cocokan model (lack of fit) adalah tidak signifikan karena nilai Prob $>$ F lebih besar dari $\alpha(0.05)$. 
209 Ahmad zubair Sultan, abram tangkemanda, Irsyad Amru Djafar, Rio Triwanto Rantepadang. Pengaruh Perlakuan Panas Terhadap Sifat Mekanis dan Struktur Mikro Paduan Alumunium Silikon
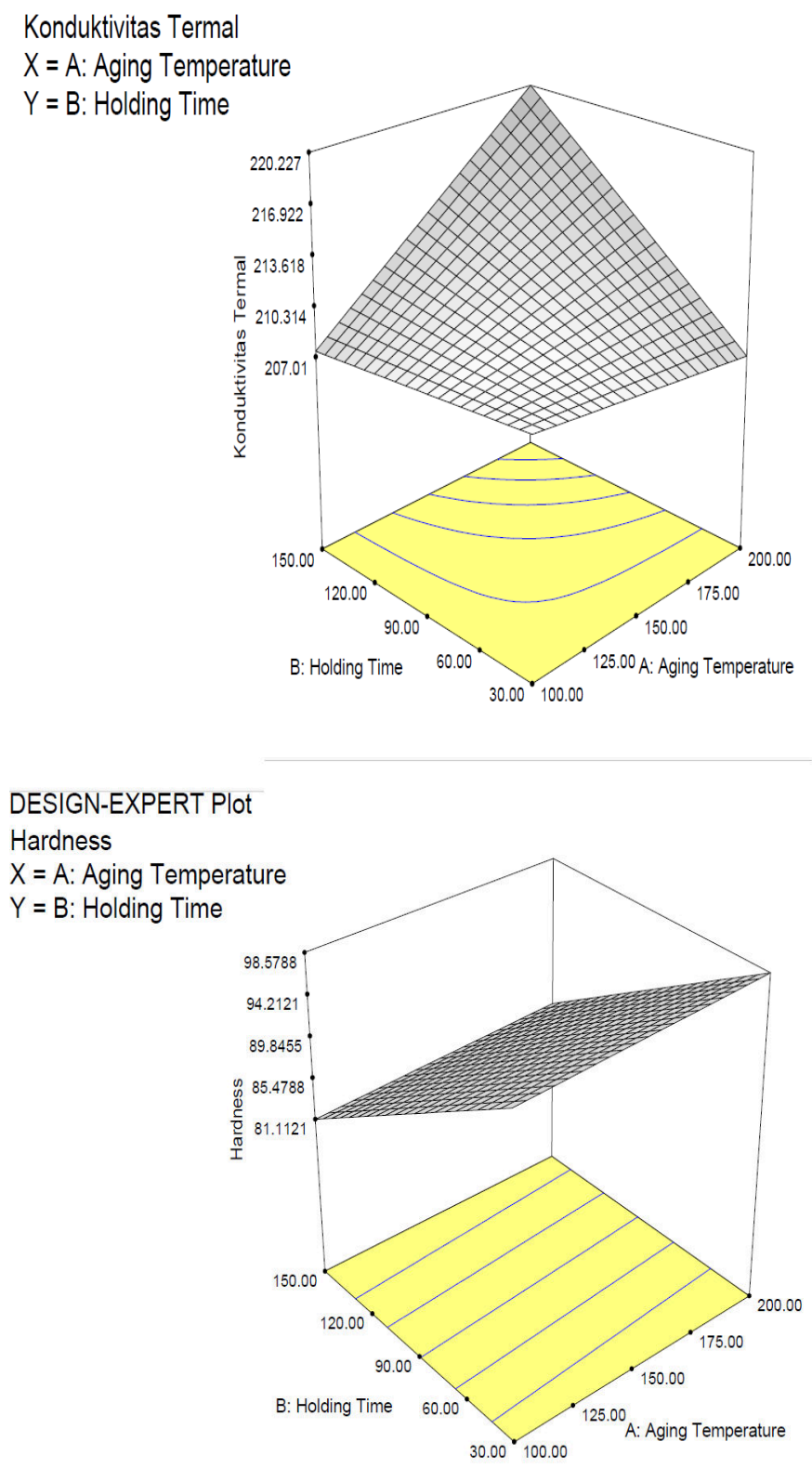

Grafik 1. Kekerasan dan konduktivitas termal terhadap holding time dan aging temperature

Gambar yang tertera pada Grafik 1 menunjkkan bahwa kekerasan tertinggi diperoleh melalui perlakuan panas solution treatment dengan diikuti aging pada temperature aging tertinggi $\left(200{ }^{\circ} \mathrm{C}\right)$ dengan waktu tahan terendah $(0.5 \mathrm{jam})$. Konduktivitas termal tertinggi dan temperatur aging tertinggi $\left(200{ }^{\circ} \mathrm{C}\right)$ dengan holding time tertinggi $(1.5 \mathrm{jam})$.

\section{Optimasi}

Optimasi bertujuan untk mencari nilai kekerasan tertinggi berdasarkan temperatur aging dan waktu tahan aging. Pengaturan untuk optimasi proses dan respon dapat dilihat pada Tabel 7 
Tabel 7. Pengaturan untuk optimasi parameter proses dan respon[5,6]

\section{Constraints}

\begin{tabular}{|c|c|c|c|c|c|c|}
\hline Name & Goal & $\begin{array}{r}\text { Lower } \\
\text { Limit }\end{array}$ & $\begin{array}{r}\text { Upper } \\
\text { Limit }\end{array}$ & $\begin{array}{l}\text { Lower } \\
\text { Weight }\end{array}$ & $\begin{array}{l}\text { Upper } \\
\text { Weight }\end{array}$ & Importance \\
\hline Aging Temper: & is in range & 100 & 200 & 1 & 1 & 3 \\
\hline Holding Time & is in range & 30 & 150 & 1 & 1 & 3 \\
\hline Hardness & maximize & 80 & 105.9 & 1.09849 & 1 & 3 \\
\hline Konduktivitas ${ }^{-}$ & maximize & 205.5 & 219.9 & 1 & 1 & 3 \\
\hline
\end{tabular}

Solusi yang diperoleh untuk batasan sebagaimana tersebut diatas diperlihatkan pada Tabel 7.

Tabel 8. Solusi yang memungkinkan untuk optimasi kekerasan[5,6]

Solutions
\begin{tabular}{ccccccc} 
Number Aging Tempel Holding Time & \multicolumn{1}{c}{ Hardness Konduktivitas } & Desirability & \\
1 & $\underline{200.00}$ & $\underline{88.12}$ & $\underline{90.7009}$ & $\underline{213.411}$ & $\underline{0.456}$ & $\underline{\text { Selected }}$ \\
2 & 100.00 & 30.00 & 97.3788 & 209.06 & 0.399 & \\
\hline
\end{tabular}

Terdapat 2 solusi yang memberikan nilai kekerasan terbaik yaitu dengan aging temperatur $200^{\circ} \mathrm{C}$ dan waktu tahan 88 menit atau temperatur aging $100 \mathrm{oC}$ dengan waktu tahan 30 menit. (Tabel 8.)

\section{KESIMPULAN}

1. Paduan Aluminium Silikon A383 memiliki unsur aluminium $73.30 \%$ dan Silikon $22.08 \%$

2. Kekerasan terbesar diperoleh pada suhu aging $200^{\circ} \mathrm{C}$ dengan waktu 30 menit dengan nilai kekerasan 105,9 HB

3. Dari hasil optimasi kekerasan terbaik yaitu dengan aging temperature $200^{\circ} \mathrm{C}$ dan holding time 88 menit atau aging temperature $200^{\circ} \mathrm{C}$ dan holding time 88 menit.

4. Seiring penambahan suhu aging, kekerasan aluminiumpun turut bertambah. Dibarengi dengan penambahn jumlah unsur silicon

\section{DAFTAR PUSTAKA}

[1] R. Bagus Suryasa M, "Pengaruh Variable Waktu (Aging Heat Treatment) Terhadap Peningkatan Kekerasan Permukaan Dan Struktur Mikro Kepala Piston Sepeda Motor Honda Vario". Fakultas Teknik Mesin. Universitas Islam 45 Bekasi, 2015.

[2] Dri Handono Sulis, "Pengaruh Temperatur Peleburan Pada Pengecororan Logam Paduan Al-Si Terhadap Kekerasan dan Struktur Mikro" Fakultas Teknik Mesin, Universitas Muhammadiyah Metro, Lampung, 2015.

[3] Mugiono, "Pengaruh Penambahan Mg Terhadap Sifat Kekerasan dan Kekuatan Impak Serta Struktur Mikro Pada Paduan Al-Si Berbasis Material Piston Bekas" Fakultas Teknik Mesin Universitas Pancasakti, Tegal, 2016.

[4] Alois Schonmetz, Karl Gruber."Pengetahuan bahan dalam pengerjaan logam”.Bandung: Angakasa. 1995, Hal 224.

[5] Prakoso, Catur "Analisis Sifat Fisis dan Mekanis Alumunium Paduan Al, $\mathrm{Si}, \mathrm{Cu}$ Terhadap Perlakuan Solution Treatment $450^{\circ} \mathrm{C}$, Quenching dengan Air, dan Aging $150^{\circ} \mathrm{C}$ ”, Tugas Akhir S-1 ,Teknik Mesin Universitas Muhammadiyah Surakarta, Surakarta. 2009, Hal 6770.

[6] Surdia T \& Saito S.,"Pengetahuan Bahan Teknik,” Jakarta: PT Pradnya Paramita, 1999. 